\title{
Striking a Balance: A Case Study of Working Women in Karachi
}

\author{
Sanam Pathan* \\ Azra Maqsood
}

\begin{abstract}
The issues associated with balancing work and family are of paramount importance to individuals, the organizations that employ them and the families that care for them. The research attempts to explore the work-life balance issues for working women and problems faced in managing work-life conflicts. Also, the objective is to determine how working women strike a balance between conflicting work-life issues. Five key factors are identified to evaluate the conflicting issues of work and life: Work Overload, Work to Life Interference, Family to Work Interference, Self Time and Caregivers Responsibilities. Furthermore, the research focuses to find what companies are doing to help working women solve their work-life dilemmas by offering, if any, flexible work arrangements.

This research study discusses the responses of a qualitative survey on work-life conflicts for working women in Karachi and which companies are doing to help them cope with these work- life challenges in the form of flexible work arrangements. The data for this survey was collected from 175 working women and also complimented with 50 in-depth interviews (semi-structured) across Karachi, from the corporate, medical and educational fields. The sampled working women had varied work backgrounds, qualification, social status, age groups, income levels, and different levels of management.
\end{abstract}

Keywords: Flexible work arrangements, working women, work-life balance, work-life conflicts

\section{Introduction}

\subsection{Background}

The understanding and public awareness about work-life balance has significantly grown in the past few years. Interestingly, the growth has been seen in the academia too, encircling varied disciplines social policy and sociology, industrial relations, psychology and even the organizational human resource management. The work-life balance plan is more comprehensive than the earlier 'family-friendly' program which focused primarily on the needs of working mothers and not covering the single working women. It is consented by all that for working women caring and other domestic responsibilities are key barrier to profitable activity for working women and are stereotyped as homemakers only (Lewis, 1997).

*Sanam Pathan is an MS student at SZABIST, Karachi

Azra Maqsood is a Professor at SZABIST, Karachi 
Work-life balance is not only about families and childcare nor is it about working less; it is about working 'smart'. about being fresh enough to give all you need to both work and home, without jeopardizing one for the other and it's a necessity for everyone, at whatever your stage in life (DTI \& Scotland Office, 2001). Furthermore, work-life balance is not just about burdensome cares: it is also about fun such as having quality time, as they say, with partners, family, intimates, having time to pursue further study, play sport, or pursue whatever interest you might have the provide you with 'balance'.

With gender roles becoming less defined, there is the opportunity for more work-life spillover. All employees, both male and female, now deal with aspects of homemaking and breadwinning. This can result in people experiencing more worry about life issues during work hours and because they feel guilty about the intrusion of their personal life on their work-life, they may also begin to experience more worry about their job during life hours. (Quick et al, 2004)

The call for balance in work and life can be witnessed today as a result of the struggles of women whose core values of intellectual curiosity and satisfaction with career forced a tipping point in our work history. No more compelling conversation for change in worklife balance exists than a woman who has spent the night awake with her crying infant or jigged to manage her personal survival against work demanding values (William \& Cooper, 2004). The core values upon which our nation is built offer the promises of equality and the pursuit of happiness to its citizens. As a result, organizations have a moral responsibility to respond to the call for continued efforts in changing the paradigm in work-life dynamics (William \& Cooper, 2004).

\subsection{Problem Statement}

The aim of the research report was to find out the work-life conflicts for working women and how they create a balance in their lives despite performing multiple roles. Moreover, to find out if the employing organizations are helping working women strike a balance between work and life by offering flexible work arrangements.

\subsection{Research Questions}

In this study the researchers analyzed the following questions pertinent to the research under study:

- What is work-life conflict?

- How work-life conflicts affect working women in general?

- Why working women face the dilemma of managing work and life balance?

- What are the key work-life conflict issues pertinent to working mothers and non married working women?

- Major challenges at work and in personal life along with the range of work-life conflicts influencing working women? 
- What are the various Flexible Work Arrangements (FWA) offered to working women and their influence on a women's life?

- $\quad$ The role of the organization, colleagues, family and associates in providing working women the support to managing both work and family life?

- $\quad$ Future of women in the work force, keeping in mind, the challenges and barriers to effective WLB?

\subsection{Objective of the Study}

The objectives of this research and study were to:

- Identify what work-life balance means to working women with varying backgrounds such as age, orientation, personal and professional status and social class.

- Determine the most significant work-life balance issues common to working women.

- $\quad$ Understand the work-life conflicting issues pertinent to working women, bifurcated into married working women and non married working women.

- Determine if the employers are helping working women manage work and life.

- $\quad$ Explore the factors contributing to healthy work-life balance for working women.

- Analyze the way working women deals with conflicting work and family demands.

- Explore the problems faced of managing Work-life Balance in the following areas:

- $\quad$ Personal (Study, Grooming, Leisure, Career)

- $\quad$ Social (Family, Friends, Close Associates, Societies)

- $\quad$ Economical (Financial)

- $\quad$ Family(Spouse, Children, Siblings, In-laws)

- $\quad$ Find out how flexible working options help cope with work and non work issues - Identify working women work-life strategy for balancing both the acts.

\subsection{Limitation of the Study}

Due to time constraints, samples will be selected from Karachi only and to have an indepth analysis, selected samples will be studied only.

\subsection{Significance of the Study}

The study will help the researcher, working women in all disciplines and across levels, lower, middle and senior to understand and better their Work-life situation and be a productive resource at work and as well as in their personal chores. 


\subsection{Research Methodology}

\subsubsection{Research Design}

The research was qualitative in nature and was based on the data gathered through both secondary and primary sources. A questionnaire was designed and distributed in various organizations all over Karachi to collect primary data. The sampling technique was convenience and the research was primarily classified as exploratory research.

\subsubsection{Theoretical Framework}

Figure Research Variables

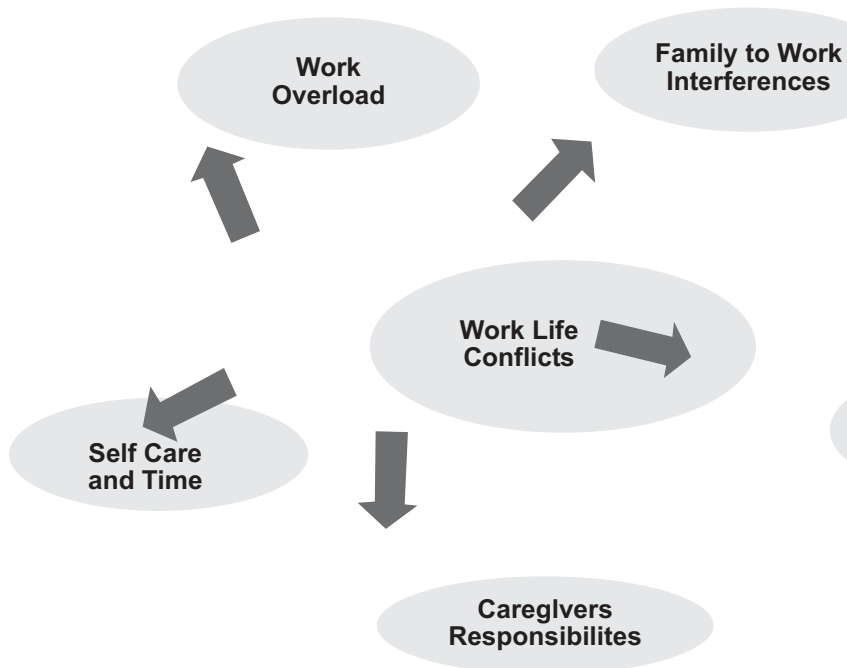

The researcher has identified five different types of work-life conflict that impacts working women in a given setup. The variables are identified as role overload, work to family interference, family to work interference, self care/time and caregiver strain.

\subsubsection{Data Collection}

\section{Primary Sources:}

- $\quad$ Sample Unit: Working Women

- $\quad$ Sampling Method: Convenience Sampling

- $\quad$ Sampling Frame: Working women from corporate, education and medical fields

- Total Sample Size: Approximately 175 working women

\section{Secondary Sources:}

Various scholarly articles, newspaper, white papers, magazines, online journals, external 
research material over the internet, past surveys, case studies and other pertinent material were considered for reference purpose and to authenticate the data gathered during the research and for the critical debate analysis.

\section{Literature Review}

\subsection{Introduction}

The topic of work-life balance is getting a great deal of attention in the academic and corporate worlds, and new research is continually being conducted. Work acts as a stimulus that creates a rewarding experience along with a tangible sense of identity for an individual. However, it sometimes results in intervening into other important areas and disciples of a person's life posing multifaceted problems. The significance of work in women's lives has shifted radically with a clear surge in professional roles, in lieu of just being homemakers, over a five decades period (Barnett \& Hyde, 2001). These changes are seen in higher education, where women are entering and graduating from professional schools at rates that are equal to or greater than men (Greenberg, 2002). White and Rogers (2000) report that the modal American family is a dual-earner family and women can expect to spend at least 30 years in the paid workforce. Despite changes in this realm of women's lives, equal advances in traditional gender roles in the home have not seen such brisk changes. Rooted in the doctrine of middle class white America in the 1950's, a woman's place was widely felt to be in the home while a man's place was in the workforce (Hochschild, 1997). Parsons (1949) presented a classic functionalist theory, claiming that a women's biological functioning predisposed her to familial and household responsibilities. Parsons and his colleagues attributed unequal marital roles to the biological fact that women bear children, and should thus remain in the home to provide childcare. Meanwhile men could not bear children, and thus found their place in the workforce. (Parsons \& Bales, 1955)

\subsection{Work and Family}

Keeping the focus of this research on working women; it is well-known to anyone who has ever done it, as to how much keeping a home and raising children or caring for an elderly dependent is a full-time job. The increasing rarity of the full-time homemaker has done more to reduce everyone's leisure time than any other factor. If both mother and father are working, someone still has to find time to make lunches, attend doctor's appointments, shop for groceries and bring meals to the table. Time at work is the single largest block of time which most people owe to others outside their family.

\subsection{Work and Life}

Work-family conflict occurs when the demands of work are in disharmony with the demands of family (Allen, 2001). In fact, work-family conflict is problematic for many working women in this country. The National Institute for Occupational Safety and Health now identifies work-family conflict as one of the ten major stressors in the workplace (Kelloway, Gottlieg \& Barham, 1999). 
In order to get a better picture of work-life balance and work family conflict faced by the working women it is important to understand what types of demands, challenges, pressures and stresses that women faces and what strategies / arrangements are availed to survive in the competitive working environment. Working women have to deal with two very different sets of demands: those that stem from their workplace (part one) and those that arise due to their non-work roles (i.e. time spent in housework, family, leisure, and volunteer activities).

\subsection{Defining Work-life Balance}

The term 'work-life balance' was coined in 1986, although its usage in everyday language was sporadic for a number of years. Interestingly, work-life programs existed as early as the 1930s. (Ranson, 2005). Rosabeth Moss Kanter's seminal book (1977), Work and Family in the United States: A Critical Review and Agenda for Research and Policy brought the issue of work-life balance to the forefront of research and organizations. In the 1980s and 1990s, companies began to offer work-life programs. While the first wave of these programs was primarily to support women with children, today's worklife programs are less gender-specific and recognize other commitments as well as those of the family.

\subsection{Defining Work-life Conflict}

Work-life conflict occurs when there is a tilt in the optimum balance of both the domains (work and life). All of us perform multiple roles of that as children, siblings, spouses, parents, coworkers, subordinates, community members, friends, etc. Interestingly, all the roles mentioned here enforce certain demands on us which (requiring resources) such as commitment, willingness, time, energy and presence.

Hence, we see that work-life conflict occurs when the collective responsibilities of these many professional and personal goals are mismatched in a given point in time and involvement in one role is made unattainable by serving the other role (Duxbury, 2003)

\subsubsection{Types of Work-Life Conflict}

According to Kossek and Ozeki, (1998) following definitions for each has been complied and presented:

Role Overload indicates that an individual has excessive work/tasks to do in a specific time period. Role overload will occur when the activities associated with the multiple roles by each individual are enormous (unachievable) to be performed simultaneously (Hutton, 1996).

Role Interference indicates that irreconcilable/conflicting demands (work and life) make it intricate for an individual to carry out the multiple roles. According to Lewis, (2001) role Interference can be e seen as occurring in two forms of an individual's life:

i. Work to Family Interference: The work responsibilities and demands 
intrudes/inhibits the attainment of family and personal life responsibilities.

ii. Family to Work Interference: The family responsibilities and demands intrudes/inhibits the attainment of work/official responsibilities.

The role interference is taken in this study to consist of two factors; one being the family to work interference and the other being the work to family interference. In the first case, interference occurs when family-role responsibilities hinder performance at work i.e. conflict at home makes concentration at work difficult. In the second case, interference arises when work demands make it harder for an employee to fulfill his or her family responsibilities i.e. preoccupation with the work role prevents active enjoyment of family life. In other words, work-life conflict is defined in this report as having two major components: the practical aspects associated with time crunches and scheduling conflicts and the perceptual aspect of feeling overwhelmed, overloaded or stressed by the pressures of multiple roles. (Wayne, Musisca \& Fleeson, 2004).

Caregiver Strain is also called as caregivers' responsibility and indicates it to anyone who provides assistance to someone else who needs it (e.g. elderly dependent, parents, children, relatives or family member with disabilities). According to Schwartzberg, \& Dytell (1996), there are four distinctive types of caregiver responsibilities resulting as a result of stress occurrence: emotional, physical, financial and family strain. The research however focuses more on the family and emotional strain.

Self Care and Time is identified as a variable that intrudes into a women's life as a personal and professional requirement to maintain and enhance the self concept and personality. By the virtue of its being, women focus on personal care and hygiene is more evident than in men. This is in part due to the societal image of women being a homemaker more than being a corporate image (Lewis, 2001). Self care is an important factor of consideration and a persistent negligence to this lead to emotional, physical and mental exhaustion occurring to the inability to create a balance in maintaining the status quo.

\subsection{Reasons for Work Family Conflict}

Work-family conflict can arise as a result of demands at work making it more difficult to accomplish tasks associated with one's family. Tasks related to family can include childcare, the care of an aging parent, household responsibilities, as well as additional responsibilities that may arise as a result of one's role within the family. Work related tasks encompass hours of paid work, and can additionally include overtime work, work related travel, and work obligations that are fulfilled at home. Work-family conflict can also be thought of as a form of conflict in which, 'role pressures associated with membership in one organization are in conflict with pressures stemming from membership in other groups' (Kahn and Long, 1988).

\subsection{Workplace Interventions in Work Family Conflict}

With both professional and personal responsibilities, women in particular are faced with 
significant challenges when reconciling these demands. People, specifically women, spend a great deal of time at work-for most people, at least 40 hours a week. Employers have great power to provide services and create workplace cultures that allow their employees to live a life that finds a balance between work and family. The way that a workplace is structured can also affect the amount of work-family conflict that people experience.

The literature considered for the purpose of research illuminates on the recognized role of the employing organizations in helping women reduce their work-family conflicts. This can range from providing a systematic dependent care programs to a mere increased levels of support for women with young children or adult care responsibilities. These are also known as Family Responsive Programs and must include legally required family leave programs. (Greenberg, 2002)

\subsubsection{Flexible Work Schedules}

Employees may have their own reasons for preferring one pattern of working time to another.

Flexible work arrangements are ranked as the most important assistance opportunity given to the working women (Allen, 2001). These arrangements permits employees to adapt their working hours in a way that helps them meet their requirements and needs as they emerge on routine basis. In order to reach an optimum balance for work and life, a lot of working women, particularly, the aware senior executives are negotiating terms with the employers without compromising on their disposal income and benefits. This is also helping them break the conventional approach towards the employees, bifurcated into men and women, and their career prospects (Canadian Council on Integrated Health Care, 2002.).

The right to request flexible working is relatively new and gives the employee the right to request a change to their working pattern and for that request to be seriously considered by the employer. Some of the most common flexible working requests are explained below.

\subsubsection{Part-time Working}

Part-time work is the most common type of flexible working and you will probably find it in most organizations and department (Greenberg, 2002). The definition of a parttime worker is someone who works fewer than 30 hours per week and they receive an equivalent reduction in pay. (Frone, 2002)

\subsubsection{Flexitime}

Flexitime is the most common form of flexible working after the option of part time working accessible to working women. Flexitime could be further discussed as being flexitime in (typically, allowing women to start their day considering their personal and professional convenience). The other type of flextime could be flexitime out, where the 
working individual is required to start the day (at the time specified in the organizational protocols) and could end the day at their own discretion/convenience. (Greenberg, 2002)

\subsubsection{Job Sharing}

Job sharing indicates a policy where two people share responsibilities, pay and all the other benefits of a full-time job. It is possible to job share in a wide range of roles and it has been proven to work across all levels of an organization-from chief executive to junior members of staff.

\subsubsection{Compressed Hours}

Compressed workweek is a relatively new concept but is gaining a lot of popularity, especially amount working women. Depending on the negotiated terms with the employing organization the individual (working women) can compress the working hours into four days of 10 hours or three and a half days of 11 or 12 hours per day (Statistics Canada, 1999).

\subsubsection{Teleworking}

Teleworking (also called home working) is a flexible work schedule where employees are permitted to work from their homes (for a few hours or all days per week). Home working can either take place on a regular or ad hoc basis, with the workplace remaining the employee's main place of work. Working from home should not be seen as a way of managing caring responsibilities at the same time. Teleworking has been seen as an excellent opportunity for working women who have to commute long hours to and from workplace. (Hill, Ferris \& Martinson, 2003)

\subsubsection{Annual Hours}

In some roles annualized hours are a possibility (Statistics Canada 1999). In quiet times, the employee works less time and then makes up the time when it is very busy. As some jobs have busy periods (at the end of the financial year, pre-Christmas, etc) it can help with the peaks and troughs of the workload.

\subsubsection{Term-Time Working}

Term-Time working allows employees to work their agreed contractual hours over term times only. Term-time working could be applicable to full- or part-time staff. Holidays are usually taken in school holiday periods only (Hill et al., 2003). However, it may be advantageous to retain between three and five days' annual leave to take more flexibly through the year.

\subsubsection{V Time}

$\mathrm{V}$ Time is voluntary reduced working time where a voluntary and temporary reduction 
in hours is requested by the employee (working women) in order to accommodate a certain number of hours required for non-work-related activities. The agreement involves a clearly defined period of time with a clear date set for returning to the standard work pattern (Parasuraman et al., 1996).

\section{Conceptual Framework of the Research}

\subsection{Introduction}

The objective of this section is to explain the conceptual framework that has been used to study the Case Study on Work-life Conflict of Working Women in Karachi. Literature survey on the research design used, formulation of the research problem and research questions, data collection, sampling frame and data analysis will be discussed in order to support the research process that has been selected.

\subsection{Research Design}

Since the research on Work-life Conflict for Working Women in Karachi is undertaken to investigate whether such concept exists, the research problem is quite open-ended, and will be addressed through a series of smaller research questions. The research describes the process of inducting theory using case studies from specifying the research questions to researching closure. Some features of the process, such as problem definition and construct validation are similar to hypothesis testing research. Others such as within case analysis and replication logic are unique to the inductive case oriented process. This research design is ethnographic while the research problem can be categorized as "unstructured".

\subsubsection{Data Collection}

Before the operationalization of data collection procedures, the research would like to describe the sampling frame that has been used to collect the data. The sample was collected from women working in various organizations. Particularly these working women were categorized as coming from the medical field (doctors, nurses, medical consultants), educationists (faculty members, primary and secondary teachers, lecturers, professors) and the corporate (trainees, officers, managers, directors, consultants working in various banks, pharmaceutical, FMGCs, IT, financial companies) both from the government and the private sectors.

\subsubsection{Data Processing and Analysis}

The background of the study is inevitably the emergence of Work-life Conflict as a necessitating issue, especially for working women as highlighted earlier.

Data collected from the questionnaire along with a set of interviews are collected, recorded and compiled. The survey conducted was mainly based on questionnaire, primarily close ended, complimented with interviews and reported in data analysis and used in deriving real time conclusion about the study under review. The research 
throughout the data collection and data reporting has tried best to prove that the analysis relies on all relevant evidence, and that all possible relevant data, as much as was available, has been sorted out and reported.

Below is the analysis of the questionnaire, in which respondents were required to indicate agreement and/or disagreement with the factors contributing to work-life conflict or hindering work-life balance.

The researcher sample size of 175 working women from Karachi has been taken and divided respondents into 3 working sets (Academics/Faculty, Corporate and Medical). Moreover, 50 interviews were conducted with working women who were also part of the respondent profile. The demographic profiling of the respondents is given below with a detailed analysis:

\subsection{Demographic}

Figure 3-1 Respondents' Highest Qualification

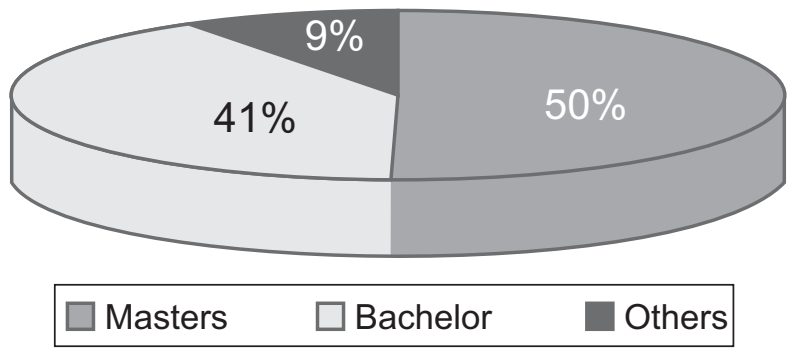

Figure 3-1 shows the highest qualification of the total respondents, 175 working women, where $41 \%$ of the women were Bachelors and $50 \%$ respondents being Masters in their respective field of interest and education. Whereas, $9 \%$ were considered, the rest comprising of academic backgrounds from the field of medicine, accountancy, consultancy, etc.

Figure 3-2 Respondents' Work Type

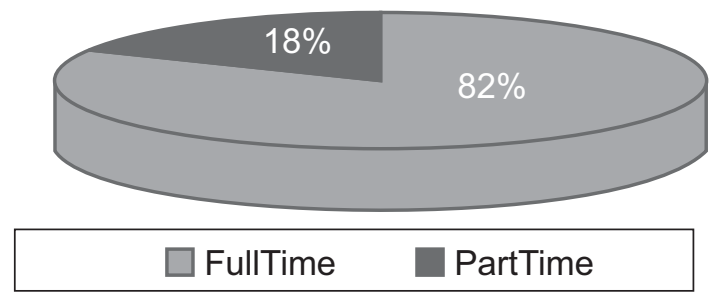

Figure 3-2 shows the respondents' work type that they are doing in their respective career. The results indicate that a majority, $82 \%$ of the working women, is pursuing a full time job and the rest $18 \%$ of the respondents were doing jobs as part timers. 


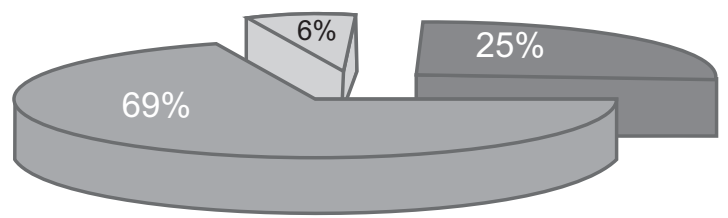

Corporate $\square$ Medical $\square$ Education

Figure 3-3 shows the respondents' professional working background. Of the total respondents of 175 sample sizes, $69 \%$ were from the Corporate (including Marketing, Finance and Accountancy, HR, Consultancy, Media, Legal and Self Employed Entrepreneurs) Professions. The other $25 \%$ of the respondents are from Education and Academic Profession (teaching in primary, schools, high schools, colleges and universities as faculty members). Rests of the $6 \%$ of respondents are from Medical field (doctors, consultants, physicians. etc.)

\section{Figure 3-4 Respondents' Nature of Organization}

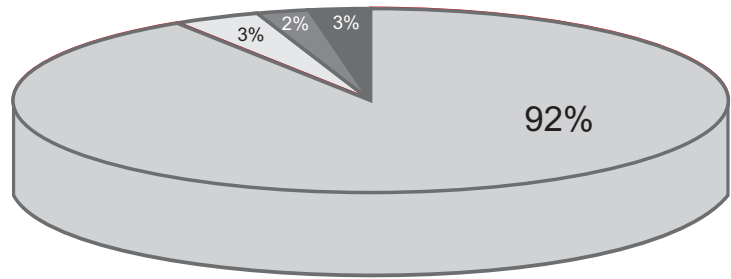

$\square$ Private $\square$ Government $\square$ Semi Government $\quad \square$ Other

Figure 3-4 shows the nature of organization in which the respondents are currently working in. The results shows that $92 \%$ of the respondents are working in private sector and only $5 \%$ are working in government and semi government sector, whereas, only $3 \%$ of the respondents worked as entrepreneurs or in some other professions.

Figure 3-5 Respondents Marital Status

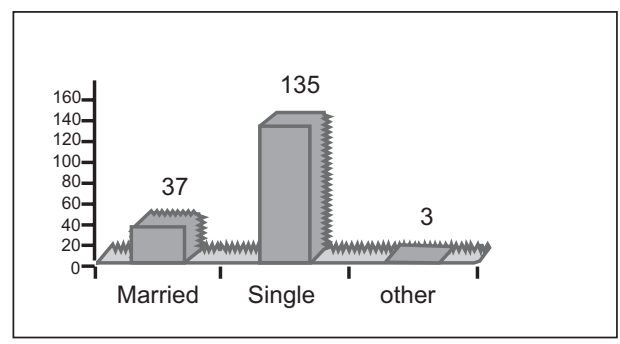

Figure 3-5 shows the marital status of the respondents. The results show that 37 working women out of 175 respondents are married, whereas 135 women are single. However, only 3 of the women are categorized as others (i.e. widow, divorced or engaged). 


\subsection{Research Factors Findings}

Figure 3- 6 Works Overload

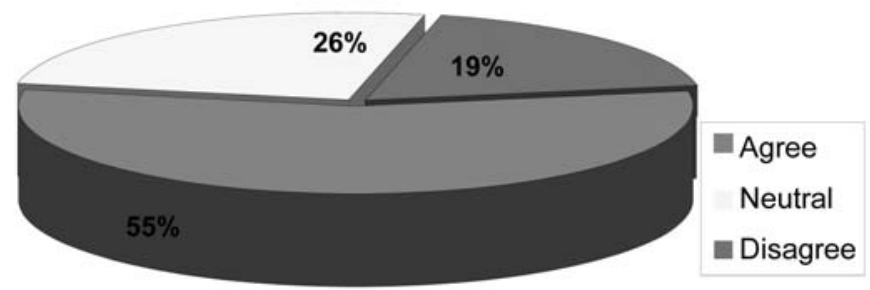

Role overload is defined as the perceptual aspect of feeling overwhelmed, overloaded or stressed by the pressures of multiple roles. Figure 3-6 shows that out of 175 respondents, $56 \%$ agreed that they are overburdened due to work. 96 felt they have to compromise on quality time with family due to work commitments. 42 respondents agreed that work is causing stress and tiredness in their lives and 49 respondents were indifferent of the stress that work overload cause to them. Analysis of each statement pertaining to Work over load it was found that overall $48 \%$ of the respondents agreed that they spent more hours at workplace then they would actually want to. Approximately $56 \%$ (98 respondents) agreed that they feel exhausted due to the lengthy hours working culture at their workplace, especially in the private sector organizations.

Figure 3- 7 Work to Family Interference

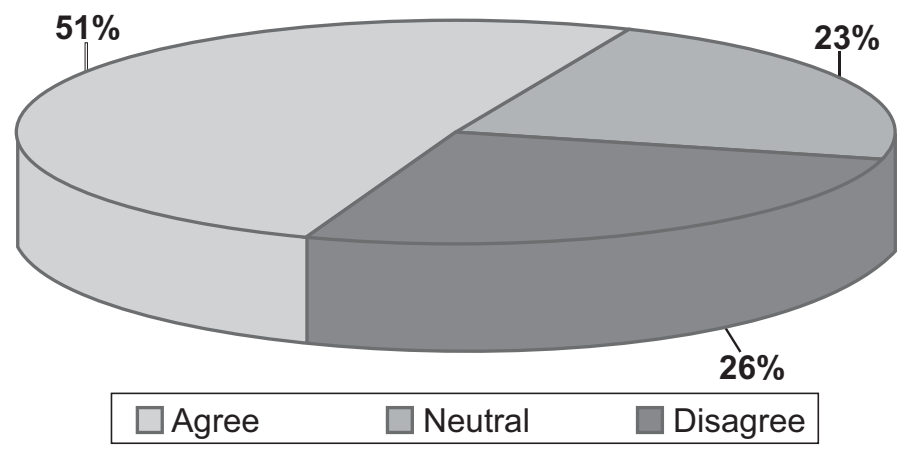

Work to Family Interference occurs when demand from work intervenes in family life, at a given point in time. Individuals who face this type of conflict meet work demands at the cost of disturbance in their family life. Figure 3-7 shows that $51 \%$ of the respondents agreed that because of their work pressure they feel too much tired. Analysis of each statement pertaining to work to family interference it was found that overall $63 \%$ respondents agreed that they cannot take part in personal and family activities because of their job commitments $56 \%$ respondents agreed that they behave nicely at home if they spend good day at work. The results show that $57 \%$ respondents agreed to have canceled personal/family activities due to work commitments. 
Figure 3-8 Family to Work Interference

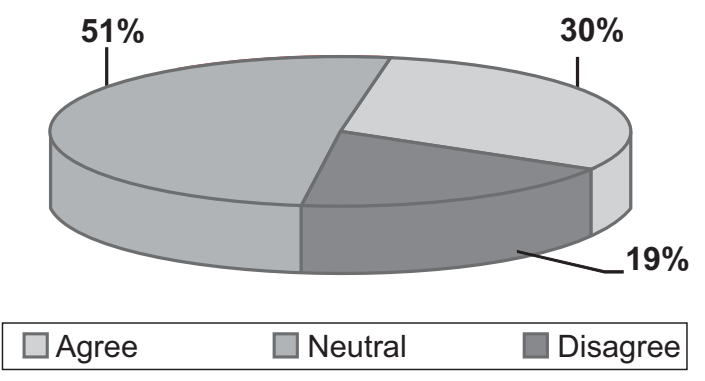

Family to Work Interference occurs when demand from family influences person's worklife, at a given point in time. Individuals who face this type of conflict meet their family commitments and responsibilities at the cost of their inhibitions in work-life. Figure 38 results show that $51 \%$ respondents disagreed that because of their personal matters their devotion toward work is distracted. Analysis of each statement pertaining to family to work interference it was found that overall $51 \%$ of the respondents disagreed that their performance at work is affected by their personal worries. $50 \%$ respondents disagreed that home chores were causing sleeplessness.

Figure 3-9 Self Time and Care

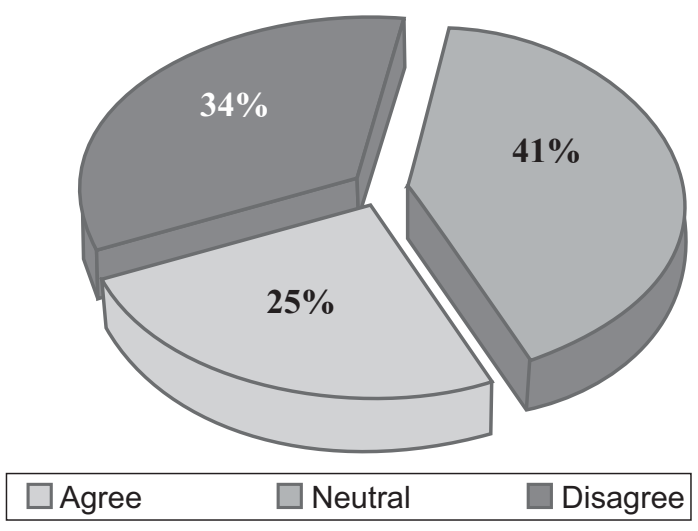

Figure 3-9 shows that $41 \%$ of the respondents agreed that they do not get time to take care of themselves after working day. The results show that overall 82 of the respondents agreed that they do take care of their grooming and image on regular basis. Analysis of each statement pertaining to self time and care it was found that overall $57 \%$ of the respondents agreed that they spend their weekend pleasantly in doing personal activities. The results show that overall 83 respondents disagreed that they go for fitness and exercise regularly. Whereas, 61 respondents said they indulge in regular exercise and fitness. In total, $40 \%$ of the respondents said they cannot manage their work stress by indulging in leisure activities. 


\section{Figure 3-10 Caregiver Responsibilities}

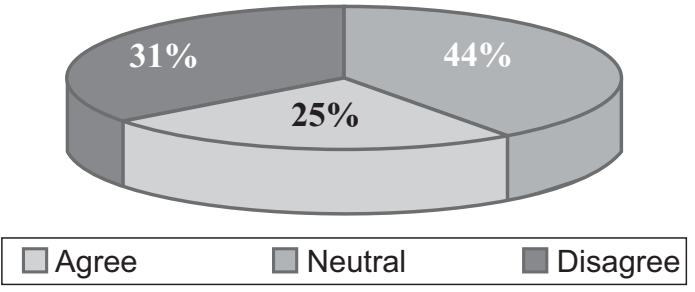

Figure 3-10 shows that $44 \%$ respondents agreed that because of work they are unable to take care of their elders and children. Analysis of each statement pertaining to caregiver responsibilities it was found that overall 63 respondents said they are able to take care of their elder/children despite work commitments. $61 \%$ respondents want to spend more time with their family. The results show that 66 respondents agreed to have responsible of food \& cooking for family. Approximately $29 \%$ respondents said that they have to look after their parents, $19 \%$ said they have a caring responsibilities of dependent adults such as grown up siblings and 33\% they have to take care of people other than the sets mentions such as relatives, in laws, disabled family members, spouses, etc. Approximately $51 \%$ of the respondents got assistance from their parents to fulfill their caring responsibilities, followed by a $25 \%$ help through hired services of servants. Spouses for married respondents played a key role for meeting the caring responsibility challenge, whereas the in-laws and friends were only $11 \%$ of the facilitation provided to the respondents for their care giver responsibilities.

\section{Figure 3-11 Employee Facilitation Program}

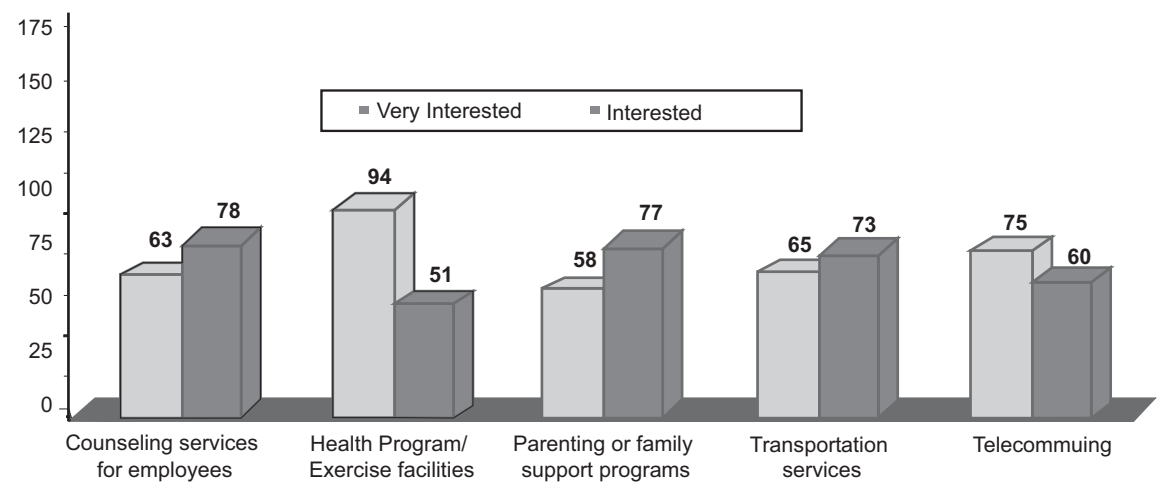

To help the respondents (working women) overcome their work-life conflict and better manage the work-life balance, the respondents were asked to voice their suggestion for employee facilitation programs, in any. Figure $3-11$ shows that $64 \%$ respondents showed a clear interest level in getting the facilitation from the employing organization. Out of the 175 approximately 145 working women wanted health programs or exercising facilities to manage their work-life conflicts. $77 \%$ respondents were very interested in parental support and facilitation from their employing organizations. It was found that $79 \%$ respondents were very interested in getting transportation facility from the 
organization that may help them cope with the commuting cost and problems. Moreover, it was found that $77 \%$ respondents were very interested in working from home and expected it to be offered from the employing organizations.

Figure 3-12 Work-life Balance Constraints

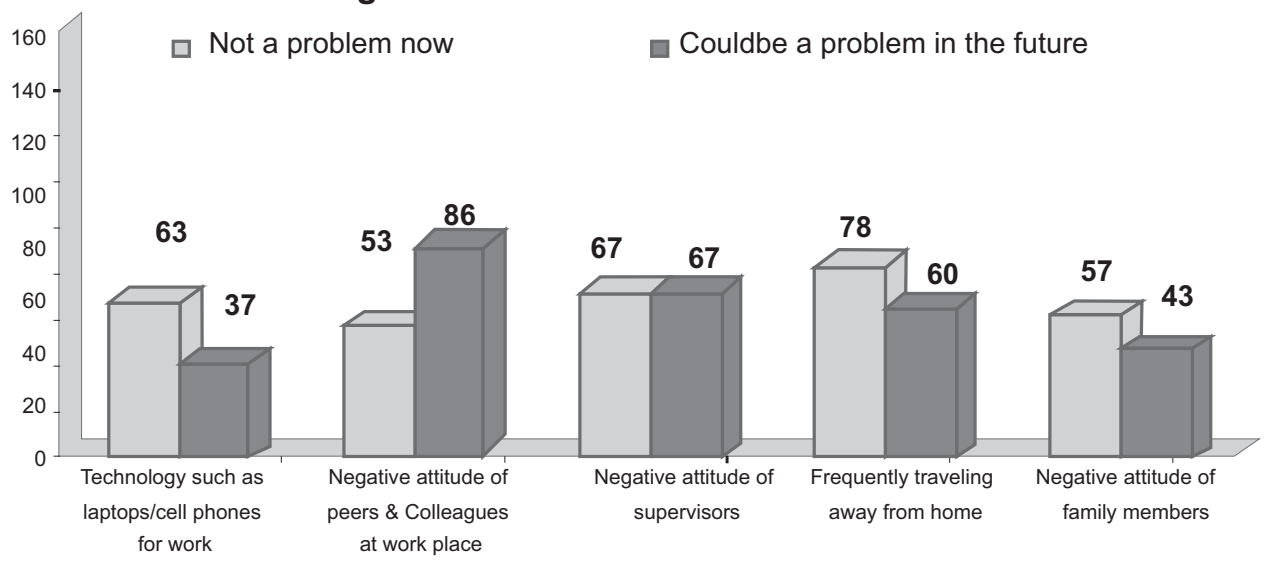

Figure $3-13$ shows $36 \%$ respondents did not see technology (connected $24 / 7$ with jobs) as a major problem, however, $21 \%$ respondents thought it could be a problem in future due to $24 / 7$ servicing. Approximately $45 \%$ respondents did not see negative attitude from supervisor as a constraint, however, $34 \%$ respondents thought it could be a problem in future due to increasing demands in the given time. 53 respondents did not find peer attitude towards them as negative however, 86 respondents thought it could be a problem in future due to increasing demands at work and with team in a given organizational setup. It was found that 67 respondents see attitude of supervisor as a potential constraint due to increasing demands at work and performance competitiveness. Negative attitude from the family was accepted by 57 respondents as not that major problem; however 43 found it was getting difficult to manage increased pressure and demands from the family side.

Figure 3-13 Major Stressors to Work-Life Conflicts

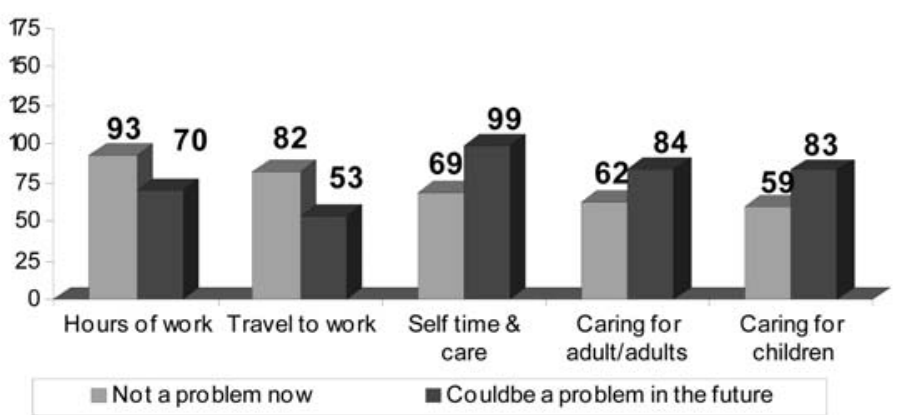

Figure 3-13 highlights the areas that were seen and identified as causes of major stress in the respondents and were made the part of the survey. The respondents were asked 
to highlight their concerns regarding hours of work, traveling to and from work, self time and care, caring for adults, caring for children as stressors inhibiting a striking worklife balance. It was found that 82 respondents did not see hours of work as a major problem, however, 53 respondents thought it could be a problem in the future if not considered as a pressing work-life issue. 53\% respondents did not see travel (commuting time) as a major problem; however, $40 \%$ respondents thought it could be a problem in the future.

\section{Conclusion and Recommendations}

\subsection{Introduction}

The last chapter of this study will conclude on the analysis of the findings of the Worklife Conflicts of Working Women in Karachi that have been reported in Chapter 3. Because the study focuses on qualitative tools (in the form of questionnaire and interviews done), the findings reported are based on the respondents' judgments, and later on, more objectively reported using the surveys, questionnaires and interviews.

\subsection{Conclusions}

After reviewing the data it can be seen that working women do face a significant worklife conflict in their routine life. Analysis shows that high work-life conflict is linked with inferior and unsatisfactory work performance, soared absenteeism, disturbed family running as well as detrimental to physical and mental health. In a nutshell, significant work-life conflict influences working women ability to balance her work and non work domains by being productive at work and at the same time enjoy and nurture their families at home.

Following observations and conclusions were drawn from the research findings under each factor analyzed:

\section{Role Overload}

The analysis shows that out of 175 respondents, 101 respondents agreed that they are overburdened due to work. 96 felt they have to compromise on quality time with family due to work commitments. 42 respondents agreed that work is causing stress and tiredness in their lives and 49 respondents were indifferent of the stress that work overload cause to them. $48 \%$ of the respondents agreed that they spent more hours at workplace then they would actually want to. Approximately 56\% (98 respondents) agreed that they feel exhausted due to lengthy hours working culture at their workplace, especially in the private sector organizations.

\section{Family to Work Interference}

The results show that $57 \%$ of the respondents agreed that because of their work pressure they feel much tired. Overall, 110 of the respondents agreed that they cannot take part in personal and family activities because of their job commitments. 98 of the respondents 
agreed that they behave nicely at home if they spend good day at work. The results show that 100 of the respondents agreed that they often cancel their personal and family activities because of work commitments.

\section{Family to Work Interference}

The results show that 102 of the respondents disagreed that because of their personal matters their devotion toward work is distracted. $51 \%$ of the respondents disagreed that their performance at work is affected by their personal worries. $50 \%$ of the respondents disagreed that home chores was causing them sleeplessness.

\section{Self Time and Care}

The results show that $49 \%$ of the respondents agreed that they do not get time to take care of themselves after working day. The results show that overall 82 of the respondents agreed that they do take care of their grooming and image on regular basis. $57 \%$ of the respondents agreed that they spend their weekend pleasantly in doing personal activities. The results show that overall 83 respondents disagreed that they go for fitness and exercise regularly. Whereas, 61 respondents said they indulge in regular exercise and fitness. In total, $40 \%$ of respondents said they cannot manage their work stress by indulging in leisure activities.

\section{Caregiver Responsibilities}

The results show that 77 respondents agreed that because of work they are unable to take care of their elders and children. 63 respondents said they are able to take care of their elder/children despite work commitments. $61 \%$ respondents want to spend more time with their family. The results show that 66 respondents agreed to have responsible of food \& cooking for family. Approximately $29 \%$ respondents said that they have to look after their parents, $19 \%$ said they have a caring responsibilities of dependent adults such as grown up siblings and $33 \%$ said they have to take care of people other than the sets mentions such as relatives, in-laws, disabled family members, spouses, etc. Approximately $51 \%$ of the respondents got assistance from their parents to fulfill their caring responsibilities, followed by a $25 \%$ help through hired services of servants. Spouses for married respondents played a key role for meeting caring responsibility challenge, whereas in-laws and friends were only $11 \%$ of the facilitation provided to the respondents for their care giver responsibilities.

\section{Flexible Work Arrangements}

Most respondents (72 per cent) intended to use flexible working in the future if possible. While many employees expressed a strong view that flexible working would be good for the employer and employee. Women who cared for dependants devoted more than double the time with caring responsibilities, despite the fact that they were all working full-time. When employees with and without caring responsibilities were compared, it was found that the carers and non-carers made similar use of flexible working practices. 
There is always the potential for work and family to affect each other. Family life can spill over into work, and work into family life. A large majority of employees felt that their family offered them support for their work. In contrast, half of them experienced conflict at home arising from pressure at work. The level of conflict between work and family life was lower among employees who used flexible working.

The research examined the relationship between the traditional male-dominated workplace culture and flexible working, psychological health, and intentions to leave the organization. Employees who perceived their workplace to be unsupportive of flexibility and family life had higher levels of conflict between work and family, as well as poorer psychological health, and stronger intentions to leave the organization.

In general, there was greater use of flexible working when employees felt that the management supported these working arrangements. Use of flexible working was associated with lower work family conflict, more positive workplace culture and more positive attitudes to flexible working practices. Managers felt that they had a greater degree of support from their own managers for flexible working than did other groups of workers. However, they were also more concerned about the career consequences of pursuing flexible working. Using flexible working arrangements was generally viewed as being positive for both employer and employee. However, employees are also seriously concerned about the effects of not working full-time on career progression and/or job security.

\subsection{Recommendations}

Work and Non Work-life cannot be studied independently. Women will have to manage work and family together as they go hand in hand. Strategies suggested should be practical in approach to be adapted by all involved in the balancing act of Work-life. We need to accept that there can be no one size fits all solution to the issue of work-life conflict and to create an optimum balance working women as well as the organizations will have to use and strategize different policies and practices in order to reduce each of the five components of work-life conflict: role overload, work to family interference, family to work interference, caregiver strain and self care and time.

Some recommendations and action plans are suggested below in the light of the study conducted and literature reviewed. It is seen and observed that senior managers who talk the most about the need for balance are the worst offenders, therefore, realistic strategies have to be implemented by the organizations and they need to:

- $\quad$ Take major steps to give equal opportunities to working women besides offering them changing roles in the family, sharing responsibilities, flexible work timings and childcare facilities.

- $\quad$ Develop and offer Employee Assistance Programmes (EAP) to facilitate professional help on personal, educational and vocational development of working women and their children.

- $\quad$ Help working women reduce and prevent stress at work by incorporating flexible work arrangements like crèches, flexitime in and out, compressed working week, 
regular medical examinations, fitness options and telecommuting.

- $\quad$ Offer innovative (work-life balance) programs to working women that will help them decrease family conflict, job problems and stress occurring at workplace. Innovative programs will include child or elder-care benefits, such as children's facilities at work sites and transportation; convenience benefits, such as on-site services like health and fitness centers, health screenings, stress management clinics, etc.

- Develop protocol and etiquette around the use of office technologies such as email, laptops and cell phones during the office hours.

- Introduce remuneration and benefits for part-time work, if that is opted as a choice of working job as part of flexible work arrangement.

- Implement cafeteria benefits packages which allow employees to select those benefits which are most appropriate to their personal situation on a yearly basis.

- Keep focus on hours rather than on output and on presence rather than on performance which will require new performance measures that focus on objectives, results and output (i.e. move away from a focus on hours to a focus on output).

- $\quad$ Publically reward and appreciate women who have successfully combined work and non-work domains.

Similarly, the working women in their respective domains need to take action and strategies that will help them reduce conflicts and improve work-life balance by focusing their efforts on the following sets of initiatives:

- $\quad$ Make work demands and work expectations more realistic by developing good time management skills and scheduling for both work and non-work tasks.

- $\quad$ Create flexibility around work by doing what stands most important in the given time and on a typical day.

- $\quad$ Focus on creating a more supportive work environment by involving others in the work and non work domains.

- $\quad$ Take advantage of supportive policies and flexible work arrangements available within your organization.

- $\quad$ Raise work-life balance issues in your discussions within the workplace and within the community by being assertive in promoting new initiative that are conducive to the entire work setup.

- $\quad$ Learn to be tactful and educated enough in dealing/managing with stress arising from work and family/ home activities. 


\section{References}

1 Allen, T. D. (2001). 'Family-Supportive Work Environments: The Role of Organizational Perceptions', Journal of vocational behavior, Vol. 58, No. 3, pp. 414-435.

2 Barnett, R. C. and Hyde, J. S. (2001). 'Women, men, work, and family', American Psychologist, Vol. 56, No. 10, pp. 781-796.

3 Canadian Council on Integrated Health Care (CCIH), 2002. A Discussion Paper on Workplace Health, CCIH: Ottawa.

4 Department of Trade and Industry (DTI) and Scotland Office (2001) The Essential Guide to Work-Life Balance. London: DTI

5 Duxbury, L. (2003). Work-Life Conflict in Canada in the New Millennium: A Status Report. Ottawa: Health Canada, www.phac-aspc.gc.ca/ publicat/worktravail/report2/index.html

6 Frone, M. (2002). 'Work-life Balance', in J. Quick and L. Tetrick (eds). Handbook of Occupational Health Psychology, American Psychological Association: Washington, D.C. pp. 143-162.

7 Greenberg, J. (2002) Managing Behavior in Organizations. Upper Saddle River, N.J.: Prentice Hall.

8 Hill, E. J., Ferris, M. and Martinson, V. (2003). 'Does It Matter Where You Work? A Comparison of How Three Work Venues (Traditional Office, Virtual Office, and Home Office) Influence Aspects of Work and Personal/Family Life,' Journal of vocational behavior, Vol. 63, No. 2, pp. 220-241.

9 Hochschild, A. R. (1997). The time bind: when work becomes home and home becomes work. New York: Metropolitan Books.

10 Hutton Raabe, P. (1996) 'Constructing Pluralistic Work and Career Arrangement' in Lewis, S. and Lewis, J. (eds) The Work-Family Challenge: Rethinking Employment. London: Sage

11 Kahn, R. L. and Long, B. C. (1988) 'Work-related stress, self-efficacy, and well-being of female clerical workers,' Counseling Psychology Quarterly, 1, pp.145-153.

12 Kanter, R. M. (1977). Work and Family in the United States: A Critical Review and Agenda for Research and Policy. New York: Russell Sage Foundation.

13 Kelloway, E. K., Gottlieb, B. H. and Barham, L. (1999). 'The source, nature, and direction of work and family conflict: A longitudinal investigation,' Journal of Occupational Health Psychology. Special Issue: Relationship between work and family life, Vol. 4, No. 4, pp. 337-346. 
14 Kossek, E. and Ozeki, C. (1998) 'Work-Family Conflict, Policies, and the Job-Life Satisfaction Relationship: A Review and Directions for Organizational Behaviour-Human Resources Research' Journal of Applied Psychology, Vol. 83, pp. 139 -149.

15 Lewis, S. (2001) 'Restructuring workplace cultures: the ultimate work-family challenge?' Women in Management Review, Vol.16, No.1, pp. 21 - 29.

16 Lewis, S. (1997) 'Family Friendly’ Employment Policies: A route to changing Organizational Culture or Playing a out at the Margins?' Gender, Work and Organization, Vol. 4, No.1, pp. 13-23.

17 Parasuraman, S., et al. (1996). 'Work and family variables, entrepreneurial career success and psychological well-being,' Journal of vocational behavior, Vol. 48, No. 3 , pp. 275-300.

18 Parsons, Talcott and Robert F. B. (1955) Family, Socialization and Interaction Process. Glencoe, Free Press.

19 Parsons, Talcott (1949) The Structure of Social Action. A Study in Social Theory and Special Reference to a Group of Recent European Writers. New York: Glencoe Free Press.

20 Quick, J. D., Henley, A. B. and Quick, J. C. (2004) 'The balancing act: At work and at home,' Organizational Dynamics, 33, pp. 426- 438.

21 Ranson, G. (2005). No longer "one of the boys": Negotiations with motherhood, as prospect or reality, among women in engineering. Canadian Review of Sociology \& Anthropology, Vol. 42, No. 2, pp. 145-166.

22 Schwartzberg, N. S. and Dytell, R. S. (1996) 'Dual-earner families: The importance of work stress and family stress for psychological well-being,' Journal of Occupational Health Psychology, Vol. 1, No. 2, pp. 211-223.

23 Statistics Canada (1999). Statistical Report on the Health of Canadians, Statistics Canada, Cat. No. H39-467/1999E: Ottawa.

24 Wayne, J. H., Musisca, N. and Fleeson, W. (2004) 'Considering the role of personality in the work-family experience: Relationships of the big five to workfamily conflict and facilitation,' Journal of vocational behavior, Vol. 64, No. 1, pp. 108-130.

25 White, L. and Rogers, S. J. (2000), 'Economic circumstances and family outcomes: a review of the 1990s,' Journal of Marriage and the Family, Vol. 62, pp.1035-51.

26 William, J. C., and Cooper, H. C. (2004) 'The public policy or motherhood,' Journal of Social issues, 60, pp. 849-865. 